\title{
A HEATED URANIUM TETRAFLUORIDE TARGET SYSTEM TO RELEASE NON-RARE GAS FISSION PRODUCTS FOR THE TRISTAN ISOTOPE SEPARATOR
}

\author{
Ronald Lee Gill
}

Ph. D. Thesis Submitted to Iowa State University

\author{
Ames Laboratory, ERDA \\ Iowa State University \\ Ames, Iowa 50011
}

Date Transmitted: October 1977

\section{PREPARED FOR THE U.S. ENERGY RESEARCH AND DEVELOPMENT ADMINISTRATION UNDER CONTRACT NO. W-7405-eng-82}




\section{DISCLAIMER}

This report was prepared as an account of work sponsored by an agency of the United States Government. Neither the United States Government nor any agency Thereof, nor any of their employees, makes any warranty, express or implied, or assumes any legal liability or responsibility for the accuracy, completeness, or usefulness of any information, apparatus, product, or process disclosed, or represents that its use would not infringe privately owned rights. Reference herein to any specific commercial product, process, or service by trade name, trademark, manufacturer, or otherwise does not necessarily constitute or imply its endorsement, recommendation, or favoring by the United States Government or any agency thereof. The views and opinions of authors expressed herein do not necessarily state or reflect those of the United States Government or any agency thereof. 


\section{DISCLAIMER}

Portions of this document may be illegible in electronic image products. Images are produced from the best available original document. 
This report was prepared as an account of work sponsored by the United States Government. Neither the United States nor the United States Energy Research and Development Administration, nor any of their employees, nor any of their contractors, subcontractors, or their employees, makes any warranty, express or implied, or assumes any legal liability or responsibility for the accuracy, completeness, or usefulness of any information, apparatus, product or process disclosed, or represents that its use would not infringe privatcly owned rights.

Available from: National Technical Information Service U. S. Department of Commerce P.O. Box 1553

Springfield, VA 22161

Price: Microfiche $\$ 3.00$ 
A heated uranium tetrafluoride target system to release non-rare gas fission products for the TRISTAN isotope separator

by

Ronald Lee Gill

A Dissertation Submitted to the

Graduate faculty in partial fulfillment of

The Requirements for the Degree of

DOCTOR OF PHILOSOPHY

Department: Chemistry

Major: Physical Chemistry

Approved :
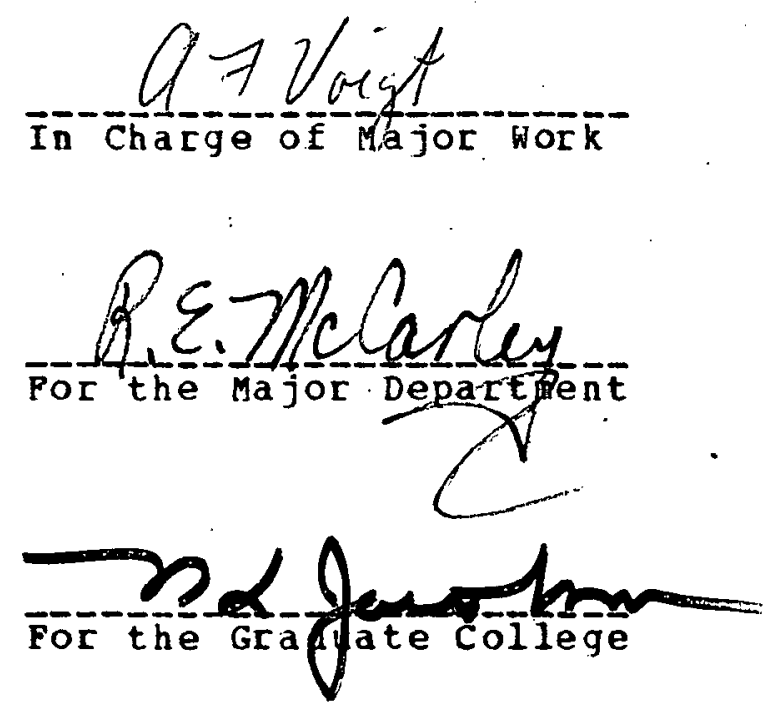

Ioya state University
Ames, Iowa

1977 
TABLE OF CONTENTS

Abstract

I. INTRODUCTION

A. The TRISTAN Isotope separator

B. Statement of : the Problem

II. OFF-LINE EXPERIMENTS

A. Experimental Procedures 14

B. Results of the off-line Experiments 16

c. Conclusions. 21

III. THE FIRST ON-LINE EXPERIMENT

A. Experimental Procedure 23

B. Apparatus 24

C. Results of the First On-line Experiment 26

D. Conclusions 29

IV. THE SECOND ON-LINE EXPERIEMNT 32

A. Experimental Procedure $\quad 32$

B. Apparatus $\quad 32$

C. Results of the Second On-line Experiment 35

D. Conclusions 39

V. DISCUSSTON . . $\quad 42$

A. Reasons for Failure 42

B. Suggestions for Improvement 4.3

VI. IITERATURE CITED 46

VII. AC KNOWLEDGMENTS 47 
Page

Table 1. Boiling points of halides of elements produced in thermal neutron fission of 23.50 .

Table 2. Approximate temperature required to volatilize certain fission products from uranium tetrafluoride.

Table 3. Temperatures required to volatilize half of the total jield from irradiated uranium tetrafluoride.

Table 4. Gaseous activity yields for uranium tetrafluoride target relative to $138 \mathrm{Xe}, 258.3-\mathrm{keV}$ transition unsaturated yield of 1000 at ambient temperature.

Table 5. Comparison of uranium tetrafluoride activity at saturation. with uranyl stearate for gaseous fission products, relative to $138 \mathrm{Xe}, 258.3-\mathrm{keV}$ transition unsaturated yield of 1000 for uranium tetrafluoride.

Table 6. Yields from surveys with a $15 \mathrm{~g} 235 \mathrm{UF}_{4}$ target. for the second on-line experiment.

Table 7. Non-gaseous fission product activities found in the isotope separator system after the second on-line experiment. 
Page

Figure 1. Layout of the TRISTAN isotope separator system.

Figure 2. Apparatus for the off-line experiments.

Figure 3. Temperature dependence of the yields for $132 \mathrm{Te}$ and $135 \mathrm{Xe}$.

Pigure 4. Target container for the first on-line experiment.

Figure 5. Target container for the second on-line experiment. 


\begin{abstract}
A heated uranium tetrafluoride target system to release non-rare gas fission products for the TRISTAN isotope separator
\end{abstract}

\title{
Ronald Lee Gill
}

\author{
Onder the supervision of Adolf F. Voigt \\ From the Department of Chemistry \\ Iowa state University
}

The development of a heated uranium tetrafluoride target system for the TRISTAN isotope separator to release non-rare gas fission products is presented. off-line experiments indicated that fluorides of As, Se, Br, Kr, Zr, Nb, Ho, TC, Ru, $\mathrm{Sb}, \mathrm{Te}, \mathrm{I}$ and $\mathrm{Xe}$ could be volatilized, but except for $\mathrm{Br}, \mathrm{Kr}$, $I$ and $\mathrm{Xe}$, none of these elements were observed after mass separation in the on-1ine experiments. The results of the on-line experiments indicated a very low level of hydride contamination at ambient temperature and consequently, uranium tetratluoride replaced uranyl stearate as the primary gaseous fission product target. possible reasons for the failure of the heated target system to yield non-rare gas activities are discussed and suggestions for designing a new heated target system are presented. 


\section{INTRODUCTION}

\section{A. The TRISTAN Isotope Separator}

The TRISTAN on-line isotope separator facility, located at the Ames Laboratory Research Reactor, began producing mass separated short-lived gaseous fission products in october 1966. It was the first such facility to become operational at a reactor. Since that time, the TRISTAN group has been involved in a systematic and detailed study of the nuclear properties of gaseous fission products as wel1 as the development of the associated equipment and technigues necessary to support such a program. The primary thrust of the program is to construct nuclear decay schemes of mass separated neutron-tich nuclides produced by thermal neutron fission of $235 \mathrm{U}$. While gammaray spectroscopy is the principal tool used in these studies, the detector array also provides the. capability of studing half-lives, beta-ray spectra, delayed neutron emission, internal conversion electron spectra and gamm-gamma angular correlations in an on-line configuration. Since the facility went into operation, the decay schemes of about 38 nuclides have been determined for fission products in the mass ranges of 85 to 93 and 136 to 143 . More than fifty publications have come out this work, with about eleven papers giving facility descriptions.

Even though the TRISTAN facility is adequately described elsewhere [1], a general description of the isotope separator 
should be given here since this work concerns itself with the development of a new target system and an interested reader may need a convenient reference. The system layout prior to July 1976 is illustrated in Figure 1.

The target is located at Face 6 of the Ames Lab Research Reactor and utilizes the external neutron beam from that beam tube. The thermal neutron flux at this port has been measured to be about $3 \times 10^{9}$ neutrons $/ \mathrm{cm}^{2} / \mathrm{sec}$. This represents about $65 \%$ of the total neutron flux, the remainder being epithermal neutrons. The target is an aluminum container with provision for an outlet to the transfer line and an inlet for xenon and krypton doped helium support gas that helps to transport the fission products as vell as sustain the plasma in the $i$ on source. Inside the target container there are aluminum trays to contain the 2350 target material; originally uranyl stearate. More than 10 grams of highly enriched uranyl stearate may be put into a single target load. Fission products which can aiffuse out of the target are transported to the ion source'via a $2-m$ teflon lined neoprene tube by the mechanism of molecular flow with some assistance from the sweeping action of the support gas: Thus only gaseous fission products can arrive at the ion source. This limits the activities available for study to xenon, krypton and their daughters, although a fresh uranyl stearate target will emanate some bromine and iodine for a period of a few weeks, 


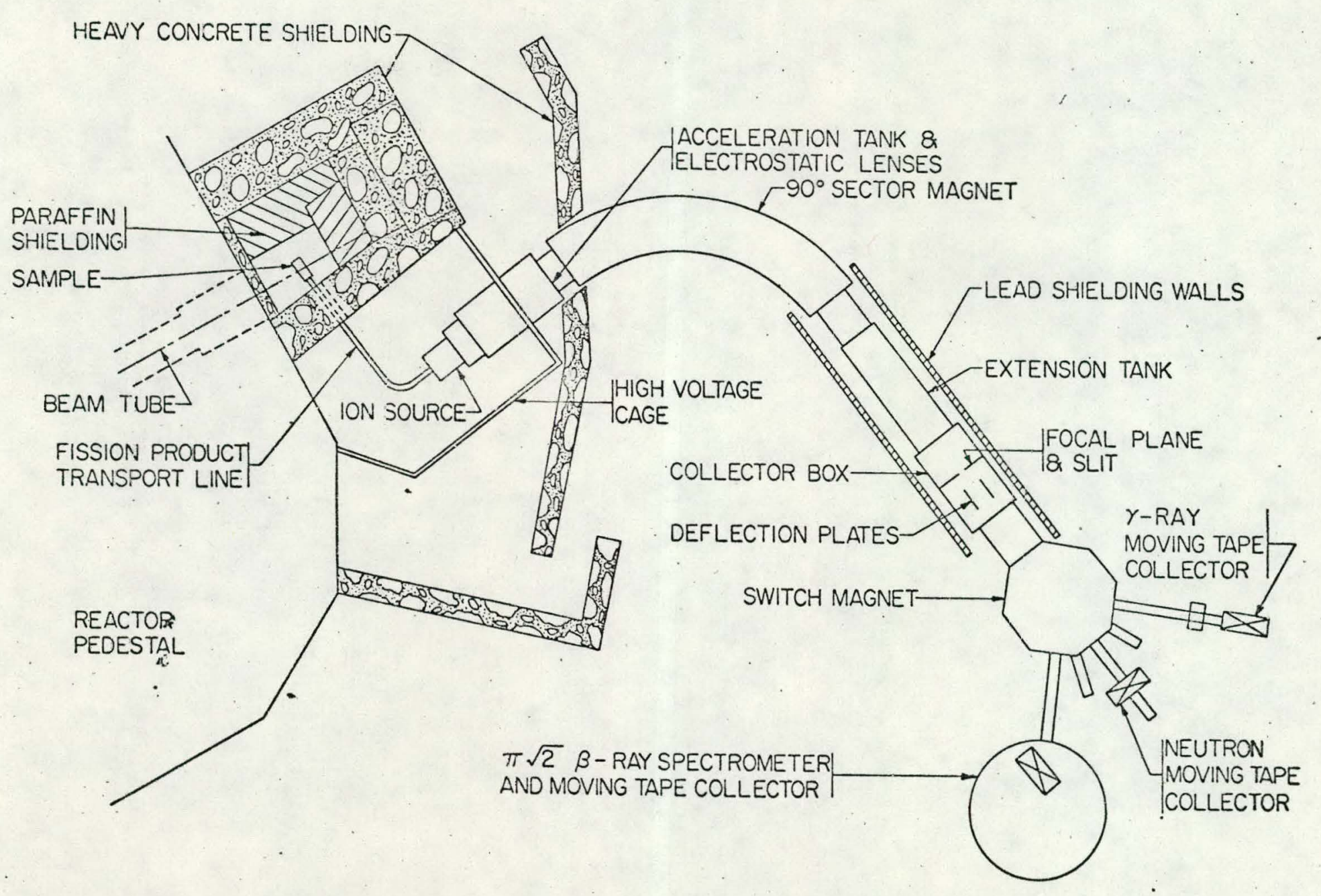

Eigure 1. Layout of the TRISTAN isotope separator system. 
at best.

The ion source operates in the oscillating electron mode [2]. The discharge chamber consists of a boron nitride (BN) inlet plate and $B N$ outlet insulators, a tantalum anode (typically operated at 40 volts), a tungsten filament (typically operated at 40 amps), a molybdenum end cap with a 1.5-mm diameter exit:hole, a stainless steel end plate and a tantalum heat shield. The support gas mentioned above is necessary since the fission product emanations alone would be insufficient to sustain a stable discharge. The xenon and krypton provide mass markers which aid in determining when the ion beam is properly focused. The ion source operates best in the 1 to 3 utorr region, but can be operated above 15 utorr, as measured at the differential pump located below the ion source.

The positive ions produced in the ion source are extracted through the exit hole by a conical electrode operated at about $5 \mathrm{kV}$. The ions are then further accelerated by an acceleration drift tube operated at $55 \mathrm{kV}$. Ion beam focusing is accomplished by means of a focus lens with a spherical electrostatic field (typically operated at $20 \mathrm{kV}$ ) and another lens with a cylindrical field (typically operated at $10 \mathrm{kV}$ ) to control the height of the beam. The vertical position of the ion beam is controlled by a pair of deflection plates 1ocated immediately before the separating magnet, with variable 
potential from -300 to +300 .

The separating magnet is a $90^{\circ}$ sector magnet ith a mean radius of $160-c m$ and a mass range of $\pm 7 \%$ of the central mass at the focal plane.

The collector box, positioned after the separating magnet, selects the particular mass to be studied by means of a 4-m slit in an aluminum plate in the focal plane of the magnet. A fluorescent screen may be lowered over the slit to observe the position and shape of the stable xenon and krypton mass markers. The shape of non-visible beams can be determined by use of a beam scanner. The beam profile is displayed on an oscilloscope and beams: of less than 300 pA current may be accurately focused. Since many experiments must be performed over a long period of time, the beam position may tend to drift. A beam position stabilizer inside the collector box senses any drift by detecting an imbalance in beam current on two adjaçent pins, separated by about 3-mm and applies a correction voltage to the acceleration voltage of the separator, thus shifting the beam position until the current on the pins balance.

After the desired mass is selected in the collector box, the beam enters the switch magnet where it is routed to one of four experimental areas. The magnet has five outlet ports at: $00, \pm 22.5^{\circ}$ and $\pm 45^{\circ}$. One of the $22.5^{\circ}$ ports is not currently in use. 
One $45^{\circ}$ port leads to a moving tape collector (MTC) where all the gama-ray spectroscopy experiments are performed. The MTC contains about 2000-m of aluminized Mylar tape with a $0.008-m$ m Al layer and a $0.025-m m$ Mylar layer. The tape may be moved forward or backwaras, at various speeds, either continuously or in discrete steps. Two stations along the tape are available for gamma-ray analysis of an activity. One is located upstream, at the point of beam deposit, and is generally used to obtain equilibrium spectra and enhanced parent spectra. The other is located downstream and, after a suitable delay, is ased to obtain enhanced daughter spectra. Both stations can accommodate two Ge(Li) detectors (1800 apart) for gamma-gamma coincidence experiments, and both may be fitted with 0.025-mm Mylar windows for low-energy spectra obtained with IEPS detectors. A windowless si(Li) detector for measuring conversion electron spectra can also be positioned at either station. This detector may be moved into the MTC vacuum in close proximity to the tape itself.

A third detector station houses a plastic scintillator and is used for beta-ray spectrum measurements. This detector is constructed so that the tape passes through the scintillating material, providing a nearly 4-pi geometry.

A seven-detector system for gamma-gamma angular.correlations may also be added to the MTC when such experiments are 
desired. The system consists of one Ge(Li) detector and six NaI(T1) detectors. A complete description of this detector system is given by Basinger et a1. [3].

A sample deposit box is located on one of the $22.5^{\circ}$ ports of the switch magnet. This box allows a collected mass to be removed from the isotope separator system for off-line analysis: This is particularly useful when a chemical separation is necessary to isolate a long-lived member of a decay chain and for preparing longer-lived gamma-ray standards for off-line use.

The suitch magnet port at $0^{\circ}$ bas been used for delayed neutron emission studies. A ${ }^{3}$ He detector and a small moving tape collector are available for experimentation at this port.

The second $45^{\circ}$ switch magnet port is connected to a double-focusing beta-ray spectrometer. The resolution of the spectrometer is sufficient to pield accurate beta-ray spectra of short-1ived nuclides, and to resolve the large number of conversion electron peaks exhibited in the decay of odd-A or odd-odd nuclei. A complete description of the spectrometer is given by Halbig et al. [4].

The overall quality of the separated beam delivered to any of the experimental stations is excellent. The only significant contamination found in a well-focused beam is due to formation of hydride ions. Formation of a hydride ion causes 
interference from the decay of activities one mass unit lower than the mass desired. Typically this contamination is on the order of a few percent, but may be as high as ten percent. In one instance, for mass 94 , the contamination from mass $93-h y d r i d e$ was estimated to be $85 \%$ of the total activity. However, this is a rather extreme case, since the fission gield of $94 \mathrm{Kr}$ is only about $20 \%$ of that for $9.3 \mathrm{Kr}$, and transport losses are nuch larger since the half-iife of $94 \mathrm{Kr}$ is only about $16 \%$ of that for $93 \mathrm{KI}$.

possibly the major short-coming of the TRISTAN facility as originally used was, as mentioned earlier, the inability of the uranyl stearate target to release fission products other than xenon and krypton.

\section{B. Statement of the Problem}

Recently, the lack of non-rare gas fission products has become a critical factor in the future of the TRISTAN facility. From a srientific point of view, there is a real need to fill in the gaps in nuclear systematics, particularly on the neutron-rich side of stability if the hope of a consistent nuclear structure theory is to be realized. There are many nuclides that have not been studied, but presumably could lend themselves to detailed study if they could be transported from the target into the ion source. From a practical 
standpoint, if the TRISTAN project is to continue, some alternatives to the rare gases must be found, since nearly all the rare gas study objectives have been achieved. Finally, the political atmosphere needs to be considered. Funding prospects for basic research in general, and the TRISTAN project in particular, are not what most scientists would consider adequate. It has become necessary to demonstrate an ability to do "frontier research" to be assured of favorable funding status. It seems reasonable, therefore, to attempt to develop a target system that can make the study of nonrare gas fission products the "frontier" for the TRISTAN facility to explore.

The development of non-rare gas capabilities proceeded along three paths: a He-jet transport system coupled to an ion source; an integrated target-ion source system that would place the ion source directly in the neutron beam; and the use of alternative target materials at higher temperatures where non-rare gas fission products may be volatile. A descriptinn of the progrege of each of these approdches is given by Talbert et al. [5]. The He-jet was considered to be a long range project, but worth pursuing. The in-beam ion source was considered the most likely approach to succeed since it would emulate the already proven system at the Studsvik, Sweden on-line facility [6]. The heated target system was considered the quickest approach to test since it 
would require minimu alteration to the existing isotope separator system. It also carried the hope of being able to control, to some extent; the chemical species volatilized by controlling the temperature. The heated target system is the topic of this thesis.

Uranium tetrafluoriae was chosen as the target material. It has good thermal stability with only two significant decomposition reactions:

$$
3 \mathrm{OF}_{4}+\mathrm{O}_{2} \rightarrow \mathrm{UO}_{2}+2 \mathrm{UF}_{6}
$$

and

$$
\mathrm{UF}_{4}+2 \mathrm{H}_{2} \mathrm{O} \rightarrow \mathrm{NO}_{2}+4 \mathrm{HF} .
$$

Reaction (1) should not occur below about $750^{\circ} \mathrm{C}$ and since the target will be under a good vacuum, there should be very little oxygen present to cause the reaction to proceed. Reaction (2) becomes spontaneous at about $250^{\circ} \mathrm{C}$. While the vacuum will keep water vapor from the atmosphere from entering the target, extrome carc must be taken to avoid the presence of water in the uranium tetrafluoride itself.

A more fundamental reason for using uranium tetrafluoride may be found by noting the low boiling points of many fluorides that could be formed in the target. As the fission fragments thermalize in the target matrix, they should pick up fluorine atoms and take on the chemical properties of 
their respective fluoride molecules at the target temperature and pressure. Table 1 lists the boiling points of halides of some elements produced in fission: A study of this table indicates that the fluorides are generally more volatile than the corresponding chlorides, bromides or iodides. Furthermore, based on a consideration of boiling points alone. As, Se, BI, Kr, Zr, Nb, Mo, Tc; Ru, Rh, Sn, Sb, Te, I and Xe could be expected to emanate from a uranium tetrafluoride target heated to about $800^{\circ} \mathrm{C}$.

A series of articles by Weber et al. $[8,9,10]$ describing the volatilization of various fission products from a uranium tetrafluoride matrix were found. They reported volatilizing Se, Kr, $\mathrm{Kr}, \mathrm{Nb}, \mathrm{Mo}, \mathrm{Tc}, \mathrm{Ru}, \mathrm{Sn}, \mathrm{Sb}, \mathrm{Te}, \mathrm{I}$ and Xe, in good agreement with what may be expected based on boiling point considerations. At temperatures of $800^{\circ} \mathrm{C}$ they reported yields of $70 \%$ to $95 \%$ with half-times between 5 and 15 seconds. Although the high yields vere promising, the long half-times ftime required for half of the total yield to be volatilized) would seem, at first glance, to eliminate the possibility of using this procedure to study activities with half-lives less than a few seconds. However, this was not expected to be a problem for two reasons. First; the target on the isotope separator is a dynamic system, that is fission products are continualiy being formed and volatilized, both from the bulk material and from surfaces, whereas in weber's 
Table.1. Boiling points of halides of elements produced in thermal neutron fission of $235 \mathrm{U}$.

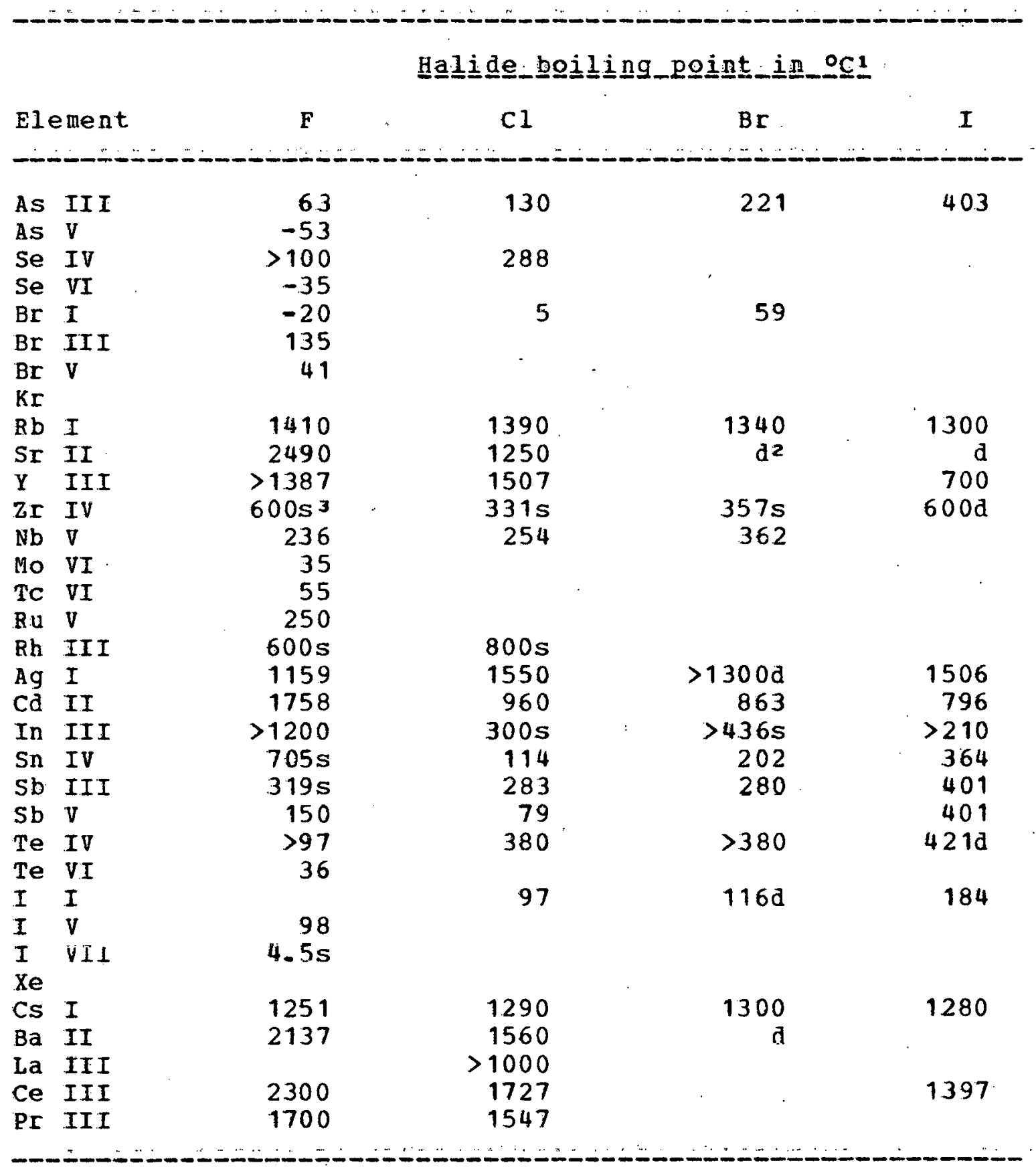

1From reference [7].

$2 \mathrm{~d}=$ decom poses.

${ }^{3} \mathrm{~s}=$ sublimes. 
experiments the samples vere irradiated and allowed to decay for a day before heating. The separator would make good use of the recoil enhanced fast diffusion of fission products near the surface of the uranium tetrafluoride matrix, but in off-line experiments, like Heber's, this effect would not be seen. Secondiy, an isotope separator does not require enormous yields from the target to provide adequate activi- . ties for study. Even if the total diffusion were slow, sufficient activity should be volatilized in a tenth-time (time required for one-tenth of the total yield to be volatilized) to make nuclear spectroscopy studies feasible.

At the onset of the project, the TRISTAN facility seemed to be the only isotope separator considering this type of target system: However, when the first on-line experiment was beginning, a parallel study by Burkard et al. [11] was brought to our attention. Although their results were negative, it seemed that the system developed and the TRISTAN isotope separator configuration was sufficiently different to warrant continued experimentation. 


\section{OFF-LINE EXPERIMENTS}

\section{A. Experimental Procedures}

After deciding to use heated uranium tetrafluoride as a target material, it was necessary to perform some off-line experiments to determine the feasibility of such a system. Knowledge of the elements that can be volatilized, the temperatures required to volatilize them and any target design restrictions that might arise as a result of the properties of uranium tetrafluoride must be obtained in order to enhance the possibilities of an on-line success. These parameters were investigated by irradiating unenriched uranium tetrafluoride, sealed in quartz vials, in the Ames lab Research Reactor for periods of one-half to one hour. The samples, consisting of less than $100 \mathrm{mg}$ of uranium, were irradiated in a pneumatic rabbit system and allowed to decay for about 24 hours before handing. The samples were heated under vacuum, to simulate the conditions present in the isotope separator target, and any volatile elements were collected on a copper disk which was cooled with liquid nitrogen and located about 10-cm above the irradiated uranium tetrafluoride. A drawing of the apparatus used is shown in Figure 2. After the heating period, the copper disk was removed and the activity collected was counted with a Ge(Li) detector to determine what elements were volatilized. In this way the volatility of various fission products could be determined as a function 


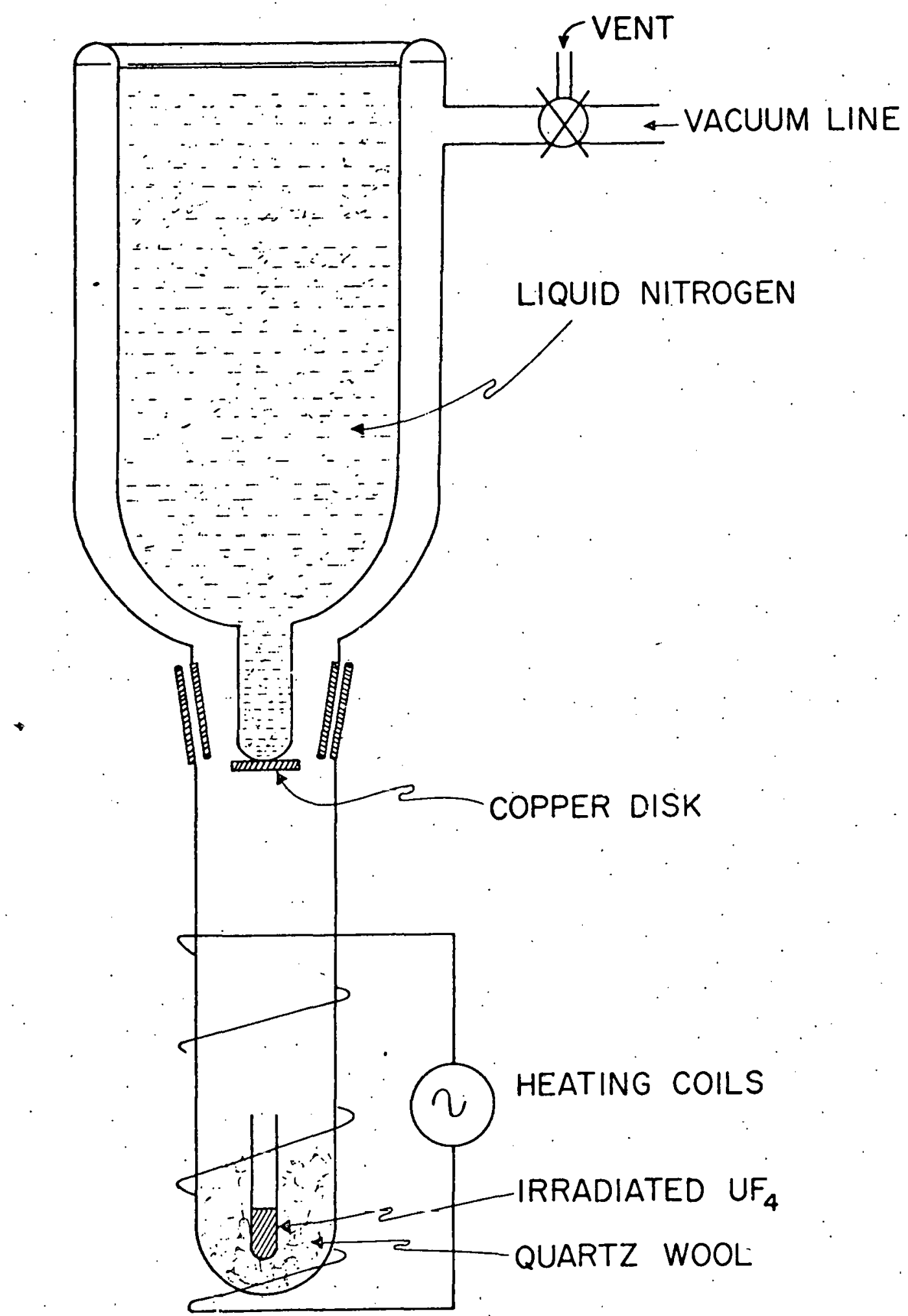

Figure 2. Apparatus for the off-line experiments. 
of temperature and heating time. The experiments were designed to be qualitative since no information was available on the overall isotope separator efficiency. Without this information, no minimum reguired yield could be established for successful use of the target system and thus, on-line tests would be required as the ultimate criterion for success or failure.

\section{B. Results of the off-line Experiments}

The off-line experiments resulted in the volatilization of $\mathrm{Zr}, \mathrm{Nb}, \mathrm{Mo}, \mathrm{Tc}, \mathrm{Ru}, \mathrm{Sb}, \mathrm{Te}, \mathrm{I}$ and $\mathrm{Xe}$ isotopes from the heated uranium tetrafluoride and their collection on the cooled copper disk. Table 2 gives the minimum temperatures at which isotopes of each element could be observed consistent1y. The minimum detectable activity was about 100 total counts, above background, in a photopeak. Typically the disk was counted for 30 minutes. The results in Table 2 agree well ith what was expected on the basis of boiling points listed in Table 1. On the basis of chemical behavior and the correlation with boiling point data, it seems reasonable that As, Se, Br, Kr and $\mathrm{Sn}$ can also be volatilized. Fission product isotopes of these elements were not observed since the half-lives are so short that they decayed asay before the experiment was performed. 
Table 2. Approximate temperature required to volatilize certain fission products from uranium tetrafluoride.

\begin{tabular}{lccc} 
& Temperature & & Temperature \\
Element & Element & \\
\hline Zr & 700 & Sb & 150 \\
Nb & 400 & Te & 150 \\
Mo & 400 & I & 150 \\
TC & 300 & & \\
Ru & 400 & &
\end{tabular}

Although the experiments were not intended to be quantitative, by normalizing yields at each temperature to the yield of a volatile element such as xenon and correcting for the amount of uranium tetrafluoride irradiated, length of decay and counting periods and the length of the irradiation, some indication of the yield versus temperature could be obtained. As expected, the yield had a threshold at some minimum temperature and rose quickly to a maximum yield at some higher temperature. Figure 3 shows the results of this treatment for $132 \mathrm{Te}$ and $135 \mathrm{Xe}$. The other elements volatilized showed similar behavior. In some cases the yields were low or the errors large enough that correction of the data gave meaningless results. The temperatures required to volatilize half the total yield are given in Table 3 for each element that yielded acceptable results. All the data used were from samples that were heated for one hour at a constant 
Table 3. Temperatures required to volatilize half of the total yield from irradiated uranium tetrafluoride.

$\begin{array}{lccc} & \text { Half-Temperature } & & \text { Half-Temperature } \\ \text { Element } & & \text { Element } & \\ & & & \\ & & & \\ \text { Mo } & 540 & \mathrm{C} & 730 \\ \text { TC } & 480 & \text { Xe } & 400 \\ \text { Sb } & 420 & 260\end{array}$

temperature.

The results of the experiments to determine the elements that could be volatilized and the temperature dependence of the yields ere essentially in agreement with the work performed by Weber et.al. [10]. However, several potential problems were indicated by these studies.

Even trace quantities of water were sufficient to convert the uranium tetrafluoride to uranium dioxide by means of reaction (2). In particular, experiments showed that there was sufficient water in the helium normally used as support gas to completely convert the uranium tetrafluoride to uranium dioxide in a relatively short time at elevated temperatures. Further experimentation shoved that if the helium was first dried by passing it through a suitable drying agent, such as magnesium perchlorate or molecular sieves, the problem could be eliminated. The simplest way of doing this would be to place a drying tube in the support gas line of 


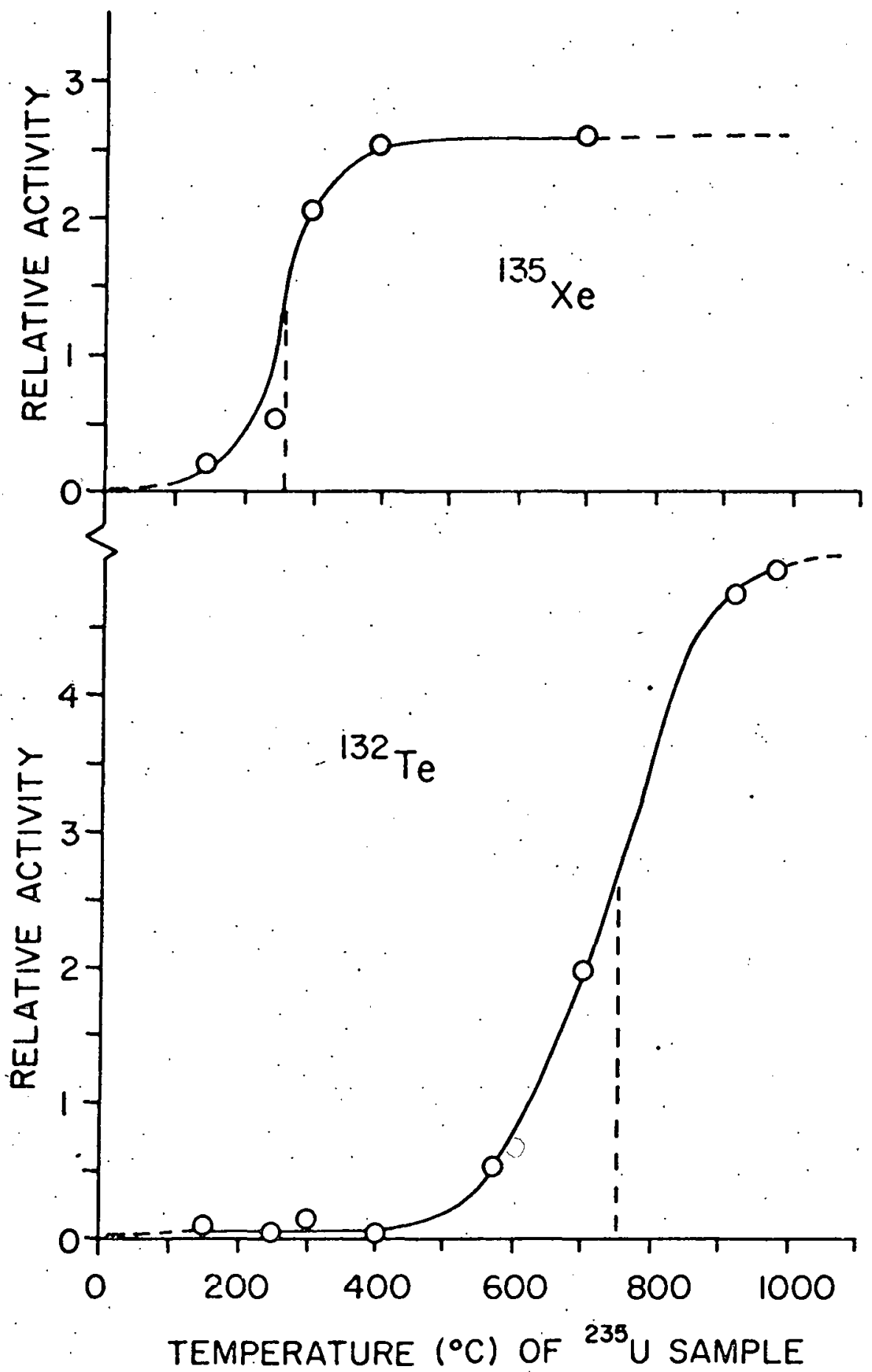

Figure 3. Temperature dependence of the yields for $132 \mathrm{Te}$ and $135 \mathrm{Xe}$. 
the isotope separator so that the helium could be aried before entering the target.

Another problem was recognized while trying to solve the oxidation problem. uranium tetrafluoride is a very finely divided powder and the addition of even a small amount of support gas is sufficient to blow it off any shelves or trays that are expected to contain it. Even simple evacuation of the target container was observed to cause the loss of nearly a11 the target material. Thus some means of mounting the uranium tetrafluoride was necessary to prevent it from becoming airborne. The use of graphite cloth and graphite cement' provided a solution to the problem. A slurry of uranium tetrafluoride and the graphite cement was made and absorbed onto a section of the cloth. This was slowly dried at about $100^{\circ} \mathrm{C}$, to prevent oxidation due to water in the atmosphere, and formed a rigid, porous material that could be impregnated with more than $100 \mathrm{mg} \mathrm{VF}_{4} / \mathrm{cm}^{2}$ with minimal losses during evacuation or addition of support gas. Irradiation and heating of a section of the impregnated cloth showed that the yields were greatly increased. The gross counting rates were increased by more than a factor of ten, with particular enhancement observed for the more volatile elements such as

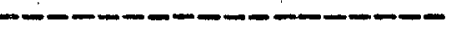

1 union Carbide Corporation, Carbon Products Division, - "UCAR" Cement Grade C-34.
} 
iodine and xenon.

Finally, it was anticipated from the beginning that transport Iine losses might be significant. To test this, a 2-m section of $1.27-\mathrm{cm}$ outside diameter stainless steel tubing was wrapped with heating tape and insulation. An irradiated piece of impregnated graphite cloth. was placed at one end and heated. The volatile fission products were collected at the other end of the tube. After the heating period, the collected fission products were observed to correspond with those expected for heating uranium tetrafluoride to the temperatures involved. While there were, of course, losses along the tube, they were not as large as had been feared and indeed the gross activity was comparable to that expected in other experiments. Thus transport from the target to the ion source was confirmed for a uniformly heated transfer line.

\section{Conclusions}

Uranium tetrafluoride absorbed onto graphite cloth was found to be a good target material. It was very stable at high temperatures, providen the system was free of both water and oxygen; with minjmal losses of target material. A wide variety of non-rare gas fission products could be released with good yield at high temperatures, in the range of 400 to 
$800^{\circ} \mathrm{C}$ and the indications were that they could be transported the reguired distance from the target to the ion source. Therefore, based on the successes of the off-line experiments, the next phase of the project, experimentation in an on-line configuration, could be justified. 


\section{THE FIRST ON-LINE EXPERIMENT}

\section{A. Experimental procedure}

The primary purpose of the first on-line heated target system was to observe non-rare gas fission products. Testing the target design for actual in-use reliability, its ability to achieve the necessary temperatures and to get some idea of the efficiency of this target system relative to the ambient temperature uranyl stearate targets normally used, were secondary purposes.

To obtain a reference point for relative yield considerations, a survey of some of the available masses was made using a large Ge(Li) detector. The survey was first made with a urangl stearate target and consisted of accumulating a gamma spectrum at each mass where sufficient activity could be produced to warrant data taking. The procedure was then repeated with the heated uranium tetrafluoride target at various temperatures. Mass chains ith no rare gas member were given special emphasia in the heaten target surveys; since observation of activity at one of those masses would give definitive evidence of non-rare gas production. Iodine and tellurium activities were carefully searched for since they were expected to be among the fission product elements easiest to volatilize. The relative intensities of gammrays from the decay of 130 Xe were used as an internal standard (since $138 \mathrm{Xe}$ is available from the isotope separator 
system) for calculating the relative efficiency of the Ge(Li) detector used in the surveys.

\section{B. Apparatus}

The target container built for the first on-line experiment is shown in a cut-away view in figure 4. The target was constructed of stainless steel, with thin walls facing the neutron beam to reduce neutron losses. An outer vacuum jacket, pumped separately from the isotope separator vacuum, served to distribute the heat evenly over the inner can which contained the uranium tetrafluoride. The vacuum jacket pumping line also served as a passageway for a thermocouple to monitor the temperature of the inner can.

A tube through the vacuum jacket and into the inner can allowed the helium support gas to enter the target. The target material was arranged on graphite cloth shelves as shown in Figure 4. In the first on-line experiment, the target was loaded with $4 \mathrm{~g}$ of 2350 as uranium tetrafluoride.

The back flange of the target was welded on after the uranium tetrafluoride was in place. The target was heated by a heating coil mounted on the brackets provided on the back flange: The target beater could be controlled independently-

A tube at the top of the target allowed volatile fission products to escape the inner can, enter the transfer line and 


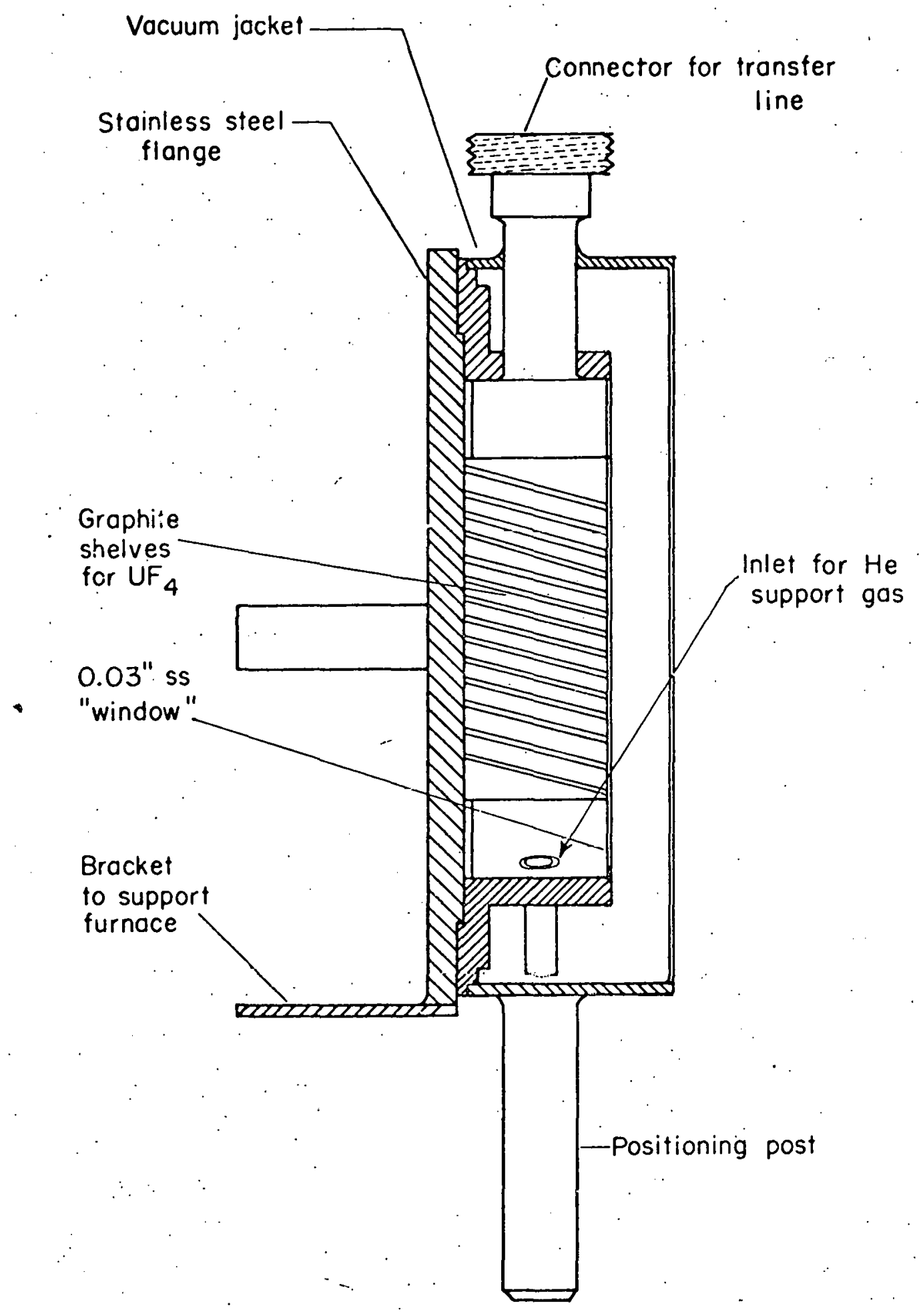

Pigure 4. Target container for the first on-line experiment. 
migrate to the ion source. The transfer line was a 2-m long stainless steel tube vith a 1.27-cm outside diameter and a 0.089-cm wall thickness. The tube was heated by wrapping it with heating tape and layers of asbestos tape for thermal insulation. The heat on each half of the transfer line, the half nearest the ion source and the half nearest the target, could be controlled independently. In this way a temperature gradient could be maintained, if desired.

\section{Results of the First on-line Experiment}

When the target was first heated, there was an enormous amount of outgassing and operation of the isotope separator became impossible for several days, until the pressure decreased to operable ranges. Throughout the runs, the ion source pressure never really stabilized to a desirable, low pressure. The pressure was always erratic, due to continual outgassing, and this made operation of the isotope separator very difficult. At one point, the acceleration voltage, normally adjusted to $55 \mathrm{kV}$, could not be raised above $35 \mathrm{kV}$ without the occurrence of arcing. This, along with the erratic ion source operation, made the ion beam focusing and isotope separator:stability very poor, requiring frequent retuning and reducing the overall efficiency of the separator system. 
Because of the poor operating characteristics, the mass surveys vere difficult to do and it was expected that the results would show large efficiency variations due to the variation of operating parameters encountered during the data taking process. In addition to the difficulties mentioned above, the target and transfer line never reached the desired temperature range of 600 to $800^{\circ} \mathrm{C}$. The highest temperature reached was $400^{\circ} \mathrm{C}$ which was high enough to volatilize, in good yield, only the most volatile of the elements desired. As the experiment proceeded, waste heat from the target ignited some plexiglas used to insulate the acceleration voltage from the ground potential shielding, causing significant damage and curtailing the experiment before any corrective measures could be undertaken.

Throughout the surveys, no non-rare gas activities were observed, other than a barely detectable amount of $136 \mathrm{I}$ observed in the uheated survey. However, gamm-ray spectra from the ambient temperature survey showed that there was no formation of hydrides, as mentioned earlier. The spectra from the heated surveys did show significant hydride formation. This was probably related to the outgassing from the target. Residual solvent, used in preparing the uranium tetrafluoride slurry, could have provided the hydrogen atoms for hydride formation to occur. 
Table 4. Gaseous activity yields for uranium tetrafluoride target relative to $138 \mathrm{Xe}, 258.3-\mathrm{keV}$ transition unsaturated yield of 1000 at ambient temperature.

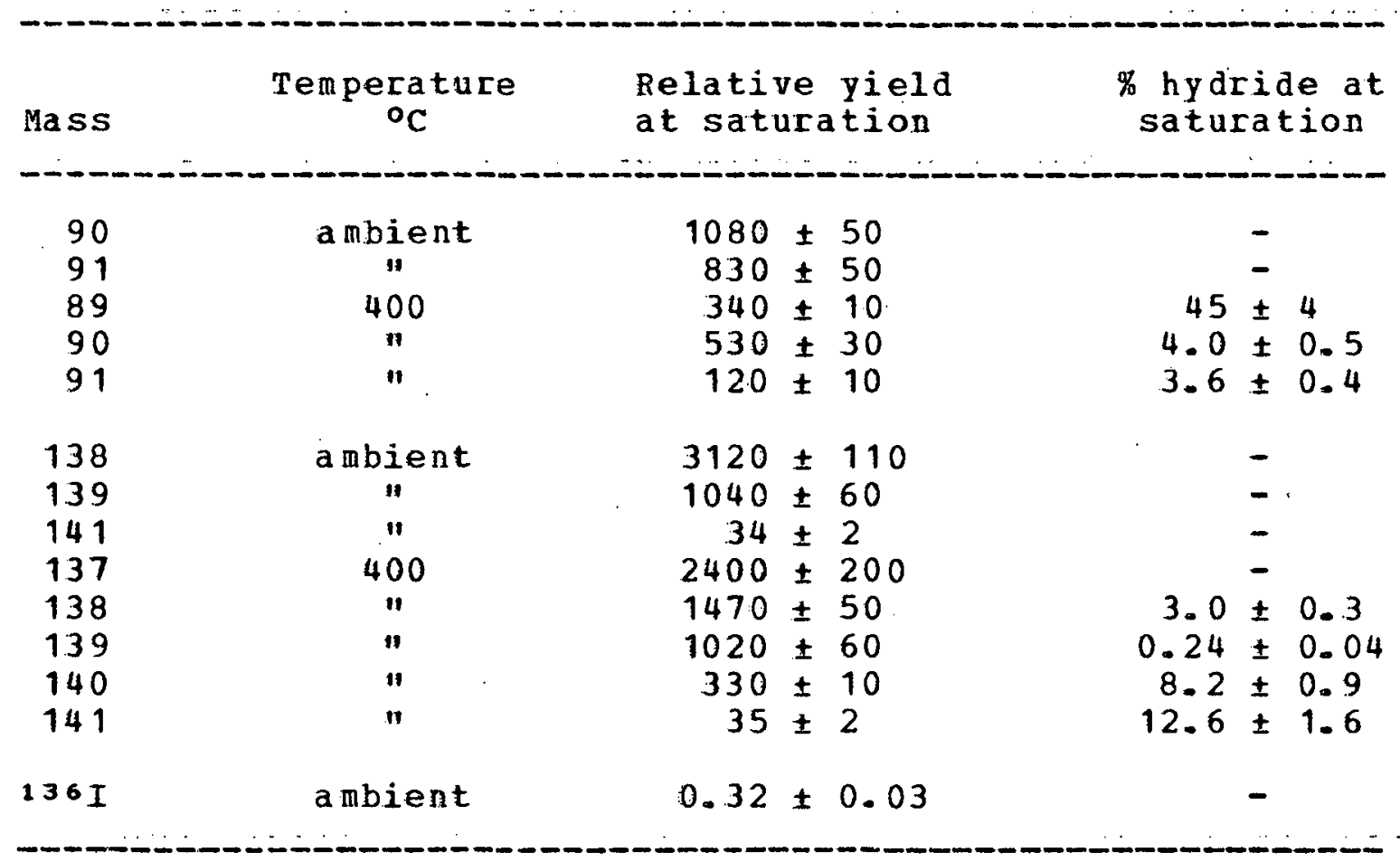

The results of the surveys at ambient temperature and for the heated target are given in Table 4. The relative yields are given as calculated at saturation activity for each mass to renove the half-life dependence of the results. The krypton:masses, 89 to 91 in Table 4, show a decrease in yield for the heated target, whereas the xenon masses, 137 to 141 in Table 4. show little change, except for mass 138, which shows a decrease: The data have not been corrected for fission yield. Doing so does not show any discernible trend, which may be attributed to the poor operating characteristics 
of this system. The $136 \mathrm{I}$ observed at ambient temperature was not observed at elevated temperatures.

Table 5 compares the relative yields for the uranium tetrafluoride target with those for the uranyl stearate target: The ratio given in the final column gives the number of grams of $235 \mathrm{U}$, as uranium tetrafluoride, required to give a yield equivalent to one gram of $235 \mathrm{U}$, as uranyl stearate. The percent hydride contamination is given to illustrate the improvement obtained by the ambient temperature uranium tetrafluoride over uranyl stearate.

\section{Conclusions}

The most serious problem to be corrected was the poor thermal efficiency of the target. Because of the large heat loss from the target, the temperature did not reach the desired range and fission products would not be volatilized from the target. The heat loss also caused the fire. Thus, it vas necessary to redesign the target to reduce heat losses so that higher temperatures could be attained and dangerous waste heat could be avoided.

It was also deemed wise to avoid the use of plexiglas as insulating material, thus eliminating the fire hazard inherent in this material. Pyrex or quartz glass can be used as effective high voltage insulation, even though it may be 
Table 5. Comparison of uranium tetrafluoride activity at saturation with uranyl stearate for gaseous fission products, relative to $138 \mathrm{Xe}, 258.3-\mathrm{kev}$ transition unsaturated yield of 1000 for uranium tetrafluoride.

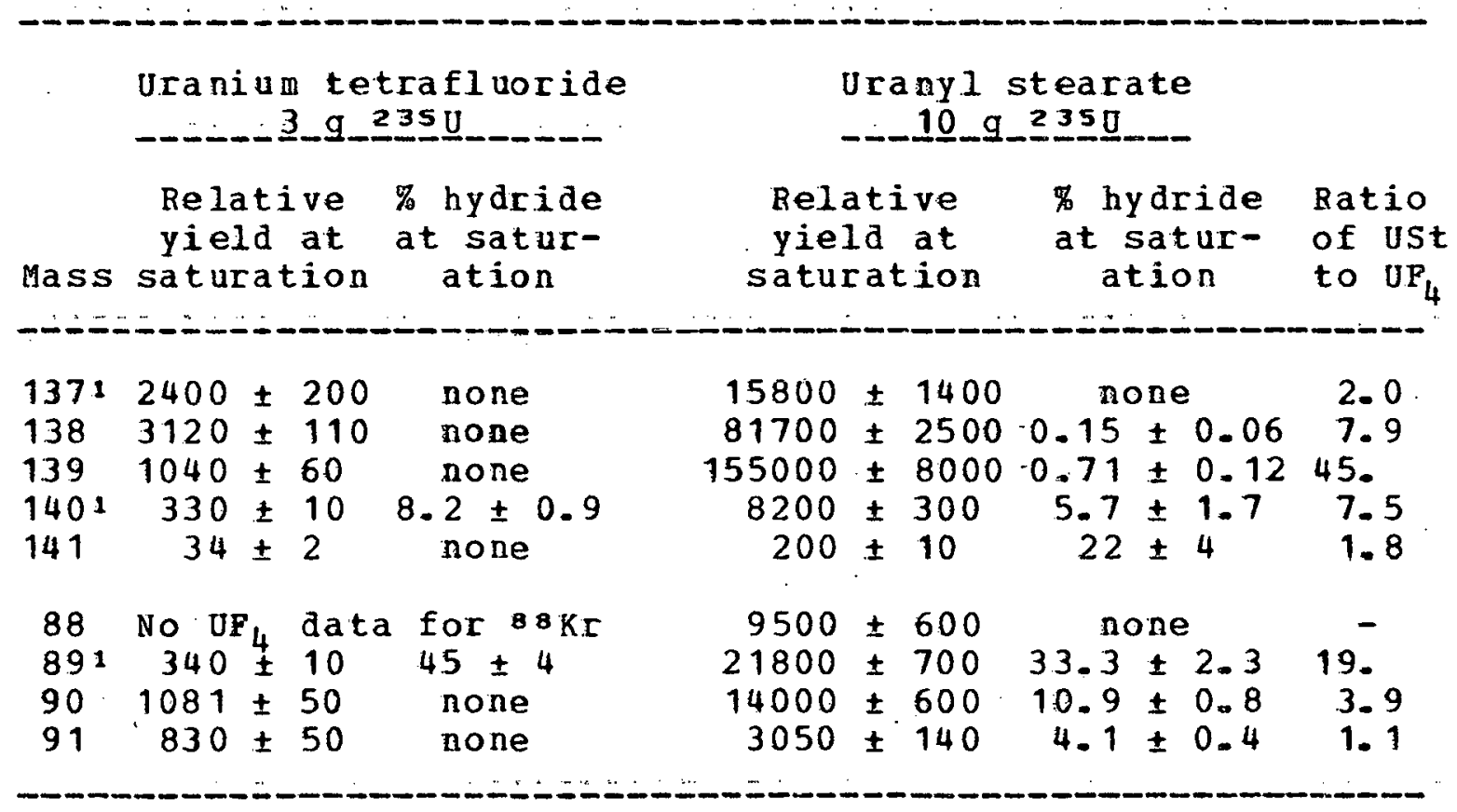

luranium tetrafluoride data indicated were taken at $400^{\circ} \mathrm{C}$.

expensive and fragile.

Another serious problem may have been transfer line losses. The tomperature of the transfer line never reached the desired level. To correct this, higher wattage heating tape should be used and more layers of asbestos, as insulation, should be wrapped around the transfer line. The amount of asbestos insulation used in the first on-line experiment was limited by the diameter of the hole through the shielding val1. This hole should be enlarged for future experiments so 
that more asbestos insulation can be wrapped over the transfer line. The heating tapes will have to be more carefully wrapped over the transfer line to eliminate some cool spots, such as places where the line was bent, which were noticed during the experiment.

Finally, since the uranium tetrafluoride target produced no hydride contamination, it was decided to use ambient temperature uranium tetrafluoride targets, in place of uranyl stearate, as the normal target material. The rare gas yields were high enough for continued rare gas studies when targets containing $25 \mathrm{~g}$ of $235 \mathrm{U}$ loaded onto 25 graphite cloth disks were used. With these targets, very little hydride contanination was observed, there was significant yield of even 10 w fission yield xenon and krypton masses, reasonable yields of iodine and some bromine could be obtained. 


\section{THE SECOND ON-LINE EXPERIMENT}

A. Experimental Procedure

The purpose of this experiment was to produce usable quantities of non-rare gas fission products and to demonstrate that the difficulties experienced in the first on-line experiment had been overcome. The reliability of the new system. was under test more than its efficiency. Uranium tetrafluoride had already been shown to be a suitable target material during the period between the first and second on-line experiments.

The mass surveys proceeded much like those in the first experiment, except that the 4-pi plastic scintillator, located inside the MTC vacuum, was used to determine the yields, and gama-ray spectra were taken to make positive identification of the nuclides present. Again, special emphasis was placed on surveying mass chains with no rare gas member to give dramatic evidence of non-rare gas production. The available masses were surveyed before heating, when the target was at temperature and again after it had cooled off, to indicate any degradation of the target material.

\section{B. Apparatus}

The Plexiglas insulation was replaced with a $30-\mathrm{cm}$ diameter pyrex cylinder and the enlarged hole through the 
shielding was fitted vith a 15-cm diameter quartz tube. There was a hole in the pyrex cylinder to allow neutrons access to the target, since pyrex contains a substantial quantity of boron. To reduce further the fire hazard, a large blower was used to exhaust farm air from the shielding cavity -

The new target is shown in Figure 5. The bend in the transfer line was made a part of the target for ease of assembly. The pumps for the vacuum jacket were placed on the other side of the shielding wall, since space inside the shielding is at a premium. The transfer line, vacuum jacket pumping line, water cooling, electrical power and thermocouples all had to come through the shielding wall via the quartz tube.

In this target, the entire target chamber was surcounded by vacuum to insulate it thermally from the outer can. The target chamber was velded shut after. $15 \mathrm{~g}$ of highly enriched uranium tetrafluoride was loaded into it. The can was heated with a $0.46-m$ diameter tungsten wire which was electrically insulated by wrapping it around ceramic posts on the target container's flange. Tantalum foil, 0.13-mm thick, served as a heat reflector.

The flange on the outer can was sealed with a water cooled o-ring. To reduce heat transfer from the inner chamber to the outer can, all the contacts between them were 


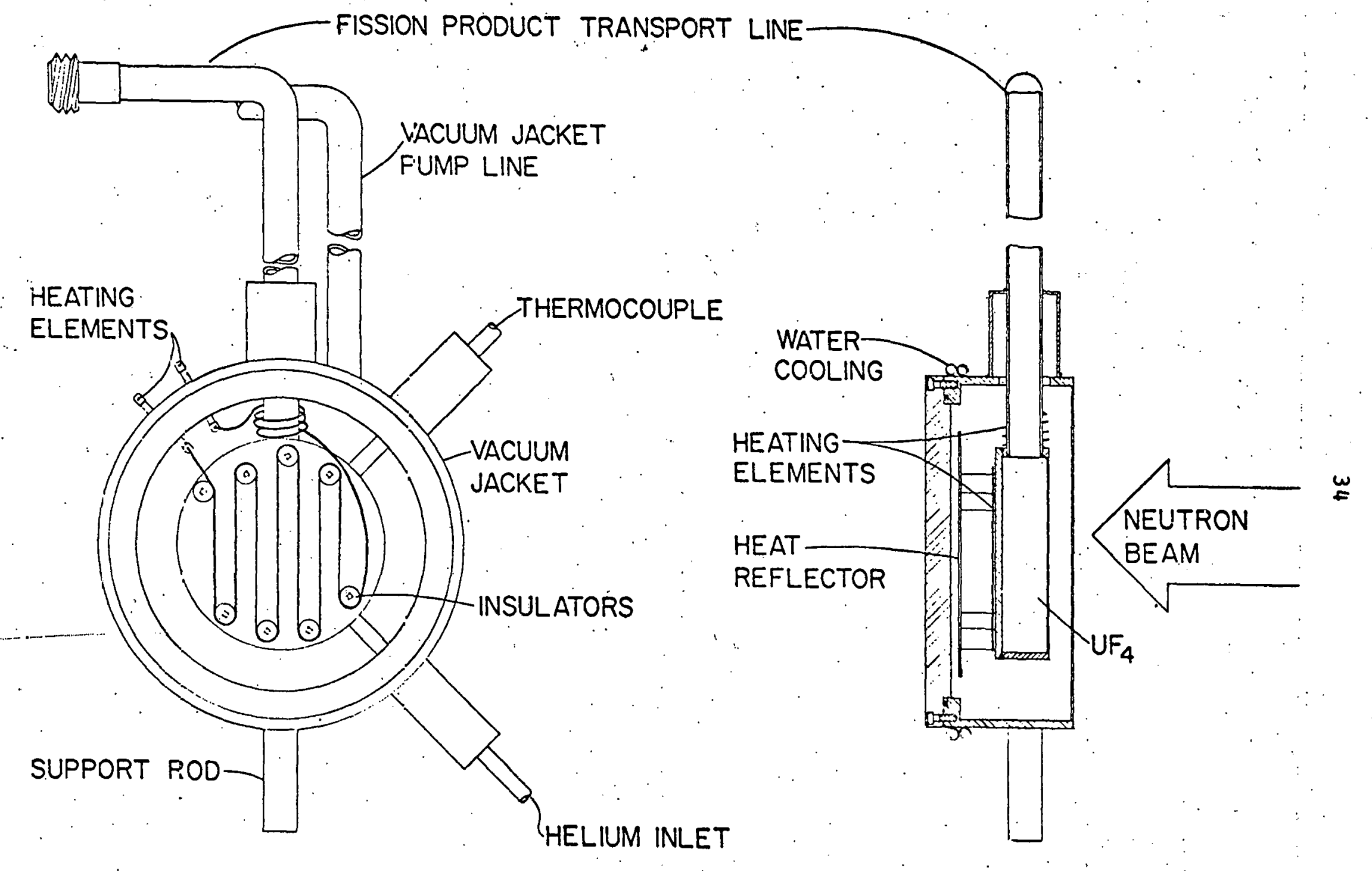

Figure 5. Target container for the second on-line experiment. 
made via thid stainless steel protrusions which established a thermal gradient.

The target was tested extensively off-line before being loaded with uranium tetrafluoride. It was determined to be leak-free, $800^{\circ} \mathrm{C}$. could be reached with relative ease, the tungsten filament had a long life time if the vacuum jacket was pumped effectively, and even at the highest internal temperatures the outer jacket aid not become significantly warm. Thus the target seemed to meet all the requirements necessary to be considered worthy of on-line operation.

\section{Results of the Second on-line Experiment}

After the ambient temperature survey was made, the target heater was turned on and the high outgassing observed in the first experiment was again observed. The pressure came down into the operating range after several days of heating. Each time the temperature was increased, there was some additional outgassing which would cease after a fev hours.

Throughout the heated surveys the transfer line was maintained at about $800^{\circ} \mathrm{C}$, while the target temperature was varied from 500 to greater than $800^{\circ} \mathrm{C}$. During the heated surveys, the isotope separator itself functioned normally with none of the arcing problems experienced in the first ex- 
periment.

In the survey made before heating, bromine and iodine were observed with good yield. However, as Table 6 shows, the yield decreased as the temperature was increased and did not return after the heat was removed. The gamm-ray spectra collected for the bromine and iodine masses were examined careful1y for evidence of selenium and tellurium, but none was found. No evidence of any other non-rare gas fission product was observed at any of the masses surveyed.

The yields tended to decrease upon heating, showed a maximum at higher temperatures, then decreased after the heat was removed. It should be noted that the survey made at $500^{\circ} \mathrm{C}$ may not be characteristic of optimum performance since the ion source pressure was higher than for the other runs due to incompleted outgassing. Hence, the $500^{\circ} \mathrm{C}$ survey yields are expected to be lower than they could have been, had the outgassing been completed.

Other, less complete, surveys were made with temperatures exceeding 8000 c. In these surveys only non-rare gas activities were searched for, using gamm-ray spectroscopy for identification. As stated above, none were found. The possibility of formation of molecular ions, vith single or multiple charges and single or multiple fluorine atoms, was explored, but no such species were observed for either rare gas or non-rare gas activities. 
Table 6. Yields from surveys with a $15 \mathrm{~g}^{2} 35 \mathrm{UF}_{4}$ target, for the second on-line experiment.

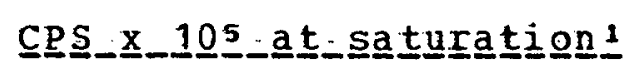

\begin{tabular}{|c|c|c|c|c|}
\hline Nuclide & $\begin{array}{l}\text { Before } \\
\text { heating }\end{array}$ & $500^{\circ} \mathrm{C}$ & $650^{\circ} \mathrm{C}$ & $\begin{array}{c}\text { After } \\
\text { heating }\end{array}$ \\
\hline $86 \mathrm{Br}$ & 0.155 & 0.006 & 0.009 & - \\
\hline $87 \mathrm{BI}$ & 0.277 & 0.001 & 0.016 & - \\
\hline $88 \mathrm{Br}$ & 0.283 & 0.001 & 0.022 & - \\
\hline $87 \mathrm{Kr}$ & 114 & 11.0 & 3.78 & 41.1 \\
\hline $\mathbf{a B}_{\mathrm{Kr}}$ & 72 & 8.5 & 177 & 44.6 \\
\hline $89 \mathrm{Kr}$ & 50.3 & 5.54 & 16.2 & 40.8 \\
\hline $90 \mathrm{Kr}$ & 299. & 4.23 & 21.2 & 67. \\
\hline $91 \mathrm{KI}$ & 7.1 & 2.08 & 51.9 & 36.0 \\
\hline $92 \mathrm{Kr}$ & 4.13 & 0.75 & 9.8 & 2.58 \\
\hline $93 \mathrm{Kr}$ & 0.499 & 0.425 & 1.29 & 0.188 \\
\hline $94 \mathrm{~K} \mathrm{~K}$ & $0.009 \pm 1.3 \%$ & 0.018 & 0.047 & - \\
\hline $135 \mathrm{I}$ & 130 & 0.008 & $0.034 \pm 4.3 \%$ & 0.002 \\
\hline $136 \mathrm{I}$ & 0.296 & 0.001 & 0.052 & 0.003 \\
\hline $135 \mathrm{Xe}$ & 1.35 & 2.67 & $0.045 \pm 4.3 \%$ & 3.85 \\
\hline $137 \mathrm{Xe}$ & 132 & 29.7 & 592 & 176 \\
\hline $138 \mathrm{Xe}$ & 157. & 73. & 470. & 117. \\
\hline $139 \mathrm{Xe}$ & 28.8 & 20.5 & 90. & 57.4 \\
\hline $140 \mathrm{Xe}$ & 67. & 19.7 & 89. & 16.2 \\
\hline $141 \mathrm{Xe}$ & 3.03 & 3.06 & 2.75 & 0.170 \\
\hline $142 \mathrm{Xe}$ & 0.323 & 0.269 & 0.480 & $0: 017$ \\
\hline $143 \mathrm{Xe}$ & 0.012 & 0.017 & 0.018 & $\ldots$ \\
\hline $14.9 \mathrm{Xe}$ & $0.001 \pm 16.6 \%$ & $0.002 \pm 7.5 \%$ & - & - \\
\hline
\end{tabular}

istandard deviations are liess than 18 , except where noted.

In all the surveys the hydride contamination was very 10w. There was no detectable hydride in the ambient temperature surveys both before and after heating. There was some observable hydride in the heated surveys, presumably associated with the outgassing, as it was worse for the lower tem- 
perature surveys where the outgassing was incomplete. For the worst case the hydride content, as determined by the amount of $90 \mathrm{Kr}$ activity in the $91 \mathrm{Kr}$ beam, was about $1 \%$. This is still significantly lower than that observed with the uranyl stearate target, as reported in Table 5.

since the system failed to produce any non-rare gas fission products, the question of whether or not any got into the ion source explored. Three days after the surveys were completed, the system vas dismantled and samples of activity found at various positions in the transfer line and ion source were counted with a Ge(Li) detector. The resulting gamma-ray spectra were analyzed to see if any non-rare gas fission products could be observed. The long-lived activities observed and their positions are indicated in Table 7.

The transport line inside the ion source, referred to in Table 7, is a stainless steel tube, about $10-\mathrm{cm}$ in length, which is inside the vacuum housing of the ion source. For practical reasons, this section could not be heated. independently and hence was heated only by conduction from the rest of the transport 1 ine and from the ion source filament. This tube represented a cool spot in the transfer line and it picked up the greatest variety of fission products. Tellurium and iodine, which were the most volatile non-gaseous fission products, were found everywhere in the system. 
Table 7. Non-gaseous fission product activities found in the isotope separator system after the second on-line experiment.

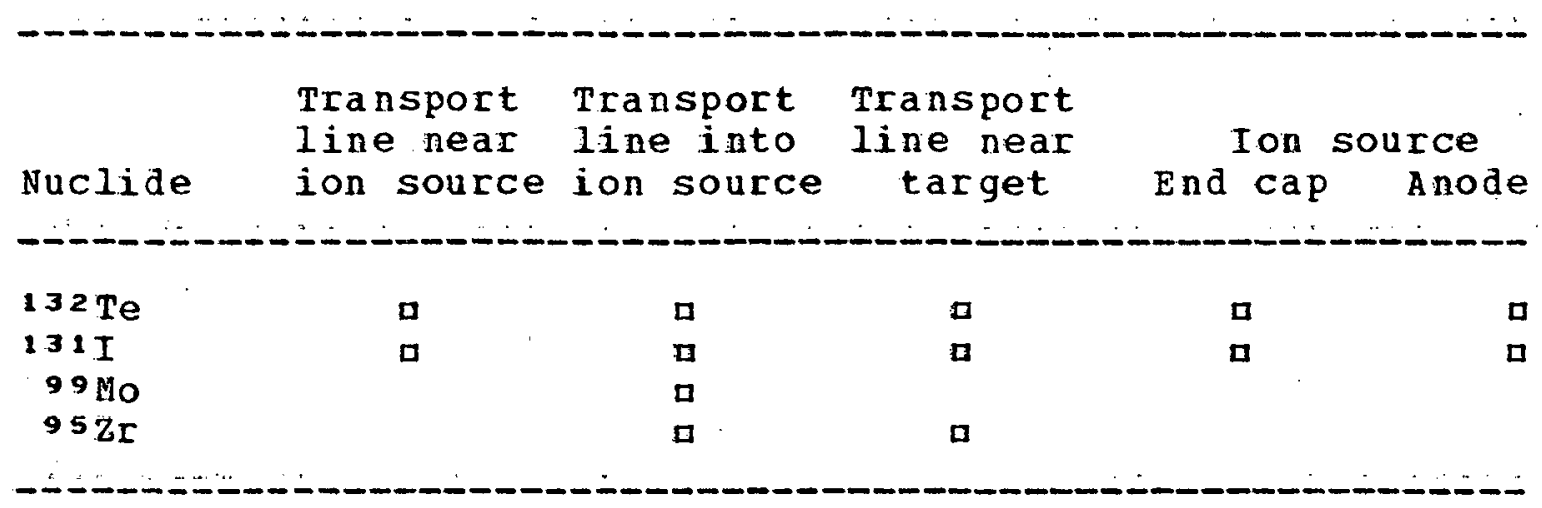

lother nuclides have half-lives too short to be observed:

The transport line near the target contained a brown viscous material which resembled a concentrated form of the solvent used in preparing the uranium tetrafluoride and graphite cement slurry. Apparently this was the cause of much of the outgassing experienced.

\section{Conclusions}

Again, no non-rare gas fission products, other than bromine and iodine, were observed after mass separation. However, examination of the dismantled system showed that non-gaseous fission products were being volatilized from the target and some vere getting into the ion source. Their absence after mass separation.suggests that an insufficient amount of fission product activity was getting into and 
coming out of the ion source, or the ion source was not efficiently breaking up the fluoride molecules, thus spreading the yield over a large number of masses representing many possible molecular ions.

Insufficient yield arriving at the ion source was probably due to cool spots along the transfer line, particularly, as indicated in Table 7, in the unheated section inside the ion source. The solvent found in the transfer line could also have impeded the transportation of fission products from the target to the ion source. Insufficient yield getting out of the ion source could be a function of the ion source construction. once an ionized atom strikes a surface, it must diffuse off that surface in order to be extracted from the ion source. If the surface does not allow easy diffusion, the ion may remain trapped inside the ion source. Both boron nitride and tantalum, the major construction materials in the ionization cavity, are considered to be materials from wich diffusion is difficult.

Since Burkard et al. [11] did observe some zirconium fluoride molecular ions in their experiments, the formation of these complex ions may seem like a reasonable explanation for the lack of success. However, this may be: discounted by two considerations. First; a very large atomic fluorine beam was observed. The beam current exceeded 30 uA and indicates ionization of large quantities of fluorine or fluoride mole- 
cules. Some fluorine could come from radiation damage to the uranium tetrafluoride target from the neutron beam. Second19. on the basis of observations from reference [11], these complex molecular ions were searched for exhaustively; but none vere found. This is an even stronger justification for concluding that" the ion source was efficiently breaking up. any fluoride molecules entering it.

Thus, the failure to observe non-rare gas fission products can be assessed to losses of activity along the transport line and onto the surfaces inside the ion source. 


\section{DISCOSSION \\ A. Reasons for Failure}

The general failure of the heated uranium tetrafluoride target system can be blamed on design restrictions imposed by the isotope separator configuration at the time of the experiments.

A major difficulty was imposed by the long transfer line required to transport volatile activities to the ion source. The length made it difficult to heat the line uniformly, and the two $90^{\circ}$ bends in the line compounded the problem even. further. Uniformly wrapping heating tape around the tube at the bends is nearly impossible, so that cool spots can be expected to form at these positions. Even if the transfer Iine could be heated uniformly, the losses due to adsorption onto the stainless steel surfaces could become a significant portion of the yield.

Some more problems arise due to the ion source design. As mentioned before, it was not practical to heat independently the tube from the ion source base to the ionization cavity, resulting in a cool area where volatile fission products could, and did, condense. Another major concern in the ion source design is the retention of fission products on the materials being used inside the ion source, particularly. boron nitride and tantalum. Fission products adhering to the anode, end cap, or other portions of the ion source may be 
unable to diffuse into the ion source plasma region, thus reducing the yield.

\section{B. Suggestions for Improvement}

The primary improvement that could be made is to shorten the transfer line. A very short, preferably straight, transfer line should greatly reduce the loss of activity before it reaches the ion source. Such a transfer line could be heated evenly by passing a high current through it if it was constructed of a thin meta1. Thinness is mentioned only in that thinner metals usually have a higher resistance and hence a higher wattage could be achieved with less current than a thicker tube of the same metal. This would eliminate the problem of maintaining uniformity of temperature encountered with heating tapes. It ould also allow the transfer line to be heated all the way into the ion source anode cavity. To avoid oxidation of the material used for the transfer line, a vacuum jacket would need to be built a round the transfer line. The jacket would also serve as thermal insulation and could be water cooled, if necessary.

The problems caused by the ion source design could be reduced by replacing the reactive boron nitride insulators with quartz and the tantalum anode with graphite. Diffusion from hot graphite is relatively easy, and the reactive sur- 
faces in the ion source could be eliminated. The design and operation of a graphite ion source differs considerably from that of the tantalum constructed "Mcconnell" ion source, but would not present any real difficulty since the earliest type of ion source used on TRISTAN was of graphite construction. The biggest drawback of these suggestions is that they require a drastic change in the isotope separator configuration. The ion source would have to be moved much closer to the neutron beam. While this would require a lot of time, effort, planning and money, these things have already been invested in the ion source relocation project, or the in-beam ion source system. The system is discussed by Talbert et al. [5] and involves an ion optics system to bring the ion beam from the ion source to the proper plane and height of the separating magnet. The ion source used is a graphite ion source, with the target on the anode. The system has the flexibility to allow the ion source to be raised slightly above the neutron beam so that a rare gas target could be used if desired. Thus it is possible to have a very short transfer line. The plans for a graphite ion source exist, although they would require considerable alteration for use with the heated target system in mind.

At the time of writing, the in-beam ion source system has been operable for 9 months and has produced successfully non-rare gas fission products, many of which could not have 
been produced by a successful heated uranium tetrafluoride target system. Therefore, there is not, at this time, a pressing need to implement these ideas for a new heated target system. 
VI. LITERATURE CITED

1. J. R. McConnell and W. L. Talbert, Jr., Nuclear Instruments and Methods 12ㅁ․ 227 (1975).

2. 0. Almen and K. 0. Nielsen, Nuclear Instruments and Methods 1, $302(1957)$.

3. G. J. Basinger, W. C. Schick, Jr, and W. L. Talbert, Jr., Nuclear Instruments and Methods 124; 381 (1975).

4. J. K. Halbig, F. K. Wohn and H. L. Talbert, Jr, , Reviey of Scientific Instruments $4 \underline{5}, 789(1974)$.

5. W. L. Talbert, Jr., F. K. Wohn, J. C. Pacer, A. RLandin, R. L. Gill, M. A. Cullison, G. A. Sheppard, K. A. Burke, K. L. Malaby and A. F. Voigt, Nuclear Instruments and Methods 1프. 257(1976).

6. S. Borg, I. Bergstrom, G. B. Holm, B. Rydberg, L. E. DeGeer, G. Rudstam, B. Grapengiesser, E. Lund and L. Westgaard, Nuclear Instruments and Methods 91. 109 (1971):

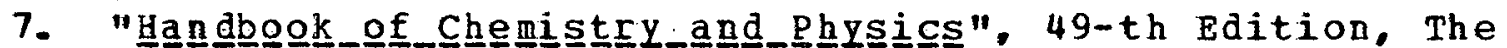
Chemical Rubber Company. Cleveland, ohio (1969).

8. M. Weber, N. Trautmann and G. Herrmann, Radiochemistry and Radioanalytical Letters $\underline{6}, 73$ (1971).

9. M. Heber, N. Trautmann, H. Menke, G. Herrmann and N. Kaffrel1, Inorganic and Nuclear Chemistry Letters 9 , $519(1973)$.

10. M. Weber, N. Trautmann, H. Menke, G. Herrmann and N. Kaffre11, Radiochimica Acta 19, 106 (1973).

11.. K. H. Burkard, H. Dumanski, R. Kirchner and E. Roeckl, Gesellschaft fur Schwerionenforschung Darmstadt, Report GSI-PB-2-74, 1974. 
VII. ACKNOWLEDGMENTS

The author wishes to acknowledge the guidance, influence and encouragement of DI. A. F. Voigt, without which none of this would have been possible. He was responsible for my interest in the TRISTAN project and was instrumental in convincing them to let me join their effort.

The suggestions and interest of Drs. W. L. Talbert, F. K. Wohn and J. C. Hill throughout the project were very helpful and encouraging. But wy did they leave town just before the second on-line experiment began?

Special thanks must go to K. L. Malaby for his work on some of the early off-line experiments. While I spent seemingly endless hours studing for prelims and was unable to perform the experiments myself, his diligence and expertise kept the project on a steady' course.

All the members of the TRISTAN group need to be thanked for their willingness to help out in any way they could. whenever they were needed. M. A. Cullison, A. R. Landin and D. R. Lekwa deserve some sort of commendation for their undauted attempts to instruct me in the art of isotope separator maintenance and operation. I hope they have enjoyed eating my guaranteed non-fattening brownies, cookies, cakes, fudge and sticky buns as much as I have enjoyed making them. Finally I need to acknowledge my daughter Erin and my wife Barbara: Erin never ate a single page of the rough 
draft of my thesis and for her, that is pretty good. Barbara put up with many weekends without me and did my-share of the housework many times over. In spite of this she seldom complained and always had encouragement to offer. 